\title{
Does contemporary canine diet cause cancer? ; A review
}

\author{
J oseph B Gentzel \\ Institute for Chronic Disease, Inc. \\ 131 Galilee Church Road, Jefferson, GA 30540, USA \\ email: josephgentzel@gmail.com \\ Received: 09-01-2013, Revised: 20-02-2013, Accepted: 21-02-2013, Published online: 04-07-2013
}

\author{
How to cite this article: \\ Gentzel JB (2013) Does contemporary canine diet cause cancer? ; A review, Vet World 6(9):632-639, doi: 10.14202/ \\ vetworld.2013.632-639
}

\begin{abstract}
Recent discoveries have discerned the presence of advanced glycation end products (AGEs) and their impact on chronic diseases that include cancer in dogs. AGEs are closely allied with chronic systemic inflammation (metaflammation). These two occurrences are observed in many cancers in both humans and dogs. AGEs are exogenous and endogenous. Exogenous AGEs occur from, among other causes, ingestion of food that is affected by the Maillard reaction in its preparation. The result is an accumulation of AGEs and progressive metaflammation that is linked with many cancers in both humans and dogs. Aspects of AGE ingestion and formation are reviewed in association with the contemporary canine diet that is primarily a kibbled meal based diet. A novel canine diet paradigm is offered as one that diminishes the AGE/ metaflammation axis. This is proposed to be less carcinogenic than the current canine diet in use by much of the civilized world. The proposed paradigm is a unique approach that offers opportunities to be tested for AGE and metaflammation accumulation that results in diminished prevalence and incidence of cancer in dogs. The paradigm diet is suggested as a prevention, treatment, and recovery aide from cancer.
\end{abstract}

Keywords: advanced glycation end products, cancer, canine diet, dogs, inflammation, maillard reaction

\section{An evolving perspective}

Recent research discoveries of advanced glycation end products (AGEs) with the generation of chronic systemic inflammation (metaflammation) on the physiology of cells that result in significant chronic disease over time is changing the paradigm for much of chronic disease. This is occurring in humans and dogs, as well as other mammals. The contribution to that pathology by exogenous AGEs in the diet is beginning to be appreciated and offering unique opportunities for prevention, treatment, and recovery in many chronic diseases including cancer. This brief report offers key information on canine diet and cancer as it relates to current evidence from this rapidly expanding area of research. Dietary factors related to chronic disease, that include cancer, are associated with these pathologies that accumulate in the body over time.

At the foundation of these chronic disease symptoms are metaflammation and AGEs with their receptor; receptor for advanced glycation end products (RAGE). This is observed in the following:

- The RAGE has been demonstrated to display significant effects on metastasis and tumor growth $[1,2]$.

- The presence of metaflammation in dogs is linked to benign hyperplasia prostrate (BHP) and prostate cancer [3].

- Serum gelatinase is associated with inflammation and tumor aggressiveness in canine tumors [4,5].

- Interleukin-8, a chemotactic cytokine as a result of

This article is an open access article licensed under the terms of the Creative Commons Attribution License (http://creativecommons. org/licenses/by/2.0) which permits unrestricted use, distribution and reproduction in any medium, provided the work is properly cited. inflammation, is proposed as a diagnostic indicator of canine mammillary tumors [4].

- Vascular endothelial growth factor (VEGF), correlated with angiogenesis and various malignancies, is directly related to unfavorable prognosis [6].

- Cancer is a chronic inflammatory disease [7-11].

- Canine obesity, a chronic systemic inflammatory (metaflammation) [12] disease, is associated with some cancers [13].

- Hickman reports that diminished inflammation via increased Omega-3 fatty acid (O3) consumption as it relates to fermentable fiber is important in decreasing intestinal inflammation and diminishing the occurrence of intestinal cancer in dogs [14].

- Much more as the evidence continues to mount by the association of physiological effects caused or contributed to by the nutrition.

There is accepted use of dogs in human research $[15,16]$. Frequently, human data and research is used and as necessary modified to be applicable to dogs [1719]. By defining the known variables and continuing to identify evolving knowledge, it is common for the work with one mammalian species to be applied to the other [20], at least as far as paradigm development is concerned. There is enough evidence to strongly suggest that the canine and human pathophysiology share enough of the same physiological principles that information from one should and could be used to suspect and test the effect on the other [1,13,17,21-23]. The differences between the species often help to clarify knowledge [18]. Gil et al [24] noted that mammals have both white and brown adipose tissue; a significant commonality. The endocrine functions of adipose tissue are being appreciated for its role in 


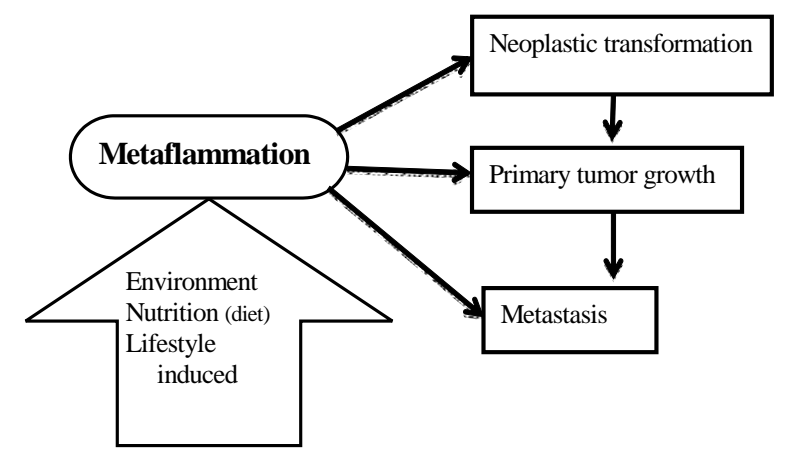

Figure-1. Metaflammation initiates and impacts all major stages of tumor progression, from neoplastic transformation to widespread metastasis. chronic disease that includes cancer [25].

There is extensive evidence linking metaflammation with many human cancers. Teté et al [26] noted the link between inflammation and cancer in humans as it relates to the nutrition of the subjects. Metaflammation creates an environment for cancer production [8] (Figure-1).

To continue further referernces linking metaflammation with chronic disease, including cancer would risk being redundant. It can be summed up that the evidence is extensive and piling up as research continues to pour into the scientific community literature supporting a significant link between cancers associated with AGEs and metaflammation that are linked to nutrition. Nutrition is a generator of both AGEs and their ligands that are linked to metaflammation [27].

\section{Primary Focus}

The primary focus of this paper is to present an evidence-based depiction for the chronic disease that arises from the consumption of contemporary canine diet. Cancer is a chronic systemic disease fueled by inflammation [11]. "The connection between inflammation and cancer has moved to center stage in the research arena," noted by Robert A. Weinberg of the Massachusetts Institute of Technology's Whitehead Institute for Biomedical Research [11]. The evidence that advanced glycation end products underlie much of the metaflammation associated with this process begins to interconnect much of this information into a cohesive paradigm. The evidence is also piling up around diet's inflammatory and AGE generating properties in both humans and dogs. As depicted in Table-1, there is association between many canine cancers with inflammation and AGEs. Along the way we will note the close association between human and canine studies of inflammation, AGEs, and cancer.

\section{Contemporary canine diet: a source of AGEs and metaflammation}

A review of the scientific literature notes that the origin of chronic disease begins in utero $[28,29]$. It is documented that AGEs occur in the fetus and increase with gestation to continue accumulating post-partum [28]. In humans, the fetus can be pre-programmed to develop chronic disease from the diet and lifestyle of the mother through a process known as developmental programming [30]. Since many mammals have similar physiological functions [31-34], there is a strong reason to suspect that the same occurs with dogs. In dogs, maternal milk is a conduit for bioactive factors passed from mother to the pup [35]. Unlike majority of humans, most puppies receive their initial post- partum diet from their mother's teats. At about 6-7 weeks that changes dramatically and from that point on the puppies eat what turns out, in many cases, to be tantamount to a toxic diet i.e. the AGE laden diet that initiates the chronic inflammation (metaflammation) process of chronic disease [3]. The process is cumulative over time [36]. Depending on their immunity; the process will soon begin to noticeably appear and will continue to accumulate as the animal ages [21]. The metaflammation that occurs secondary to the AGE process is marked by inflammatory markers [37]. Inflammatory markers are low at birth, but by three months they rise to adult levels [22].

\section{Maillard reaction}

The heating of food changes its chemical structure and produces exogenous AGEs; a process known as the Maillard reaction [38]. Proteins and fats are more sensitive to this process than carbohydrates [39]. Cooking with moist heat (vs. dry heat), using shorter cooking times, cooking at lower temperatures, and by use of acidic ingredients such as lemon juice or vinegar will diminish AGE formation [39]. Rendering of animal meat and bone to produce meal is the opposite of this scenario. Rendering has negative effects on protein and fat quality [40]. Add to that the pelleting of almost all animal food products; it has to be high AGE content [41]. Pelleting also decreases mineral absorption from meal [41].

Acrylamide is a carcinogenic compound that can be a byproduct of cooking at high temperature [42]. Protein and fats are easily affected along with sugars and the amino acid asparagine (found in large amounts in potatoes, cereal grains, glucose containing foods) [43]. The Maillard reaction' $[42,44]$ is behind this change. Most dry pet foods contain cereal grains or white potatoes. They are processed at high temperatures $\left(200-300^{\circ} \mathrm{F}\right.$ at high pressure during extrusion; baked foods are cooked at well over $500^{\circ} \mathrm{F}$ ). This is a supportive 
medium for the Maillard reaction. Acrylamide is a concern and the AGE/ metaflammation axis cause much chronic disease over time in both humans and pets.

\section{AGEs}

AGEs appear to be at the foundation of chronic disease and generates metaflammation seen chronic diseases including aging [45]. Chronic disease in dogs and humans results from or is greatly contributed to by glycation and the formation of AGEs with their RAGE [46]. This occurs both endogenously and exogenously in humans [47,48] and other mammals [49,50]. Endogenously produced AGEs occur from high glycemic states (diabetes), aging, renal failure, inflammation, and hypoxia [51]. There is a circular relationship between inflammation and AGEs. Exogenously, one the greatest source of AGEs is the diet [47]. Taken together (exogenous \& endogenous) they can be and are lethal. This AGE, RAGE, and inflammation process is at the base of chronic disease problems observed in humans and dogs $[21,46]$. Some of the consequences from AGEs are:

AGEs accumulate in the body over time causing damage and destruction [21].

AGEs have an adverse effect on the vascular endothelium [52].

AGEs are one of the prime reasons for aging [21].

AGEs are involved in the formation of chronic diseases including cancer [53].

\section{Metaflammation (chronic systemic inflammation)}

Metaflammation and acute inflammation are two very different processes with quite different effects on the body [54]. Eggar and Dixon note that lifestyle related and environmental inducers play a role in metaflammation [55]. The development of a chronic inflammatory state (metaflammation) is central to the development of many chronic diseases in dogs and humans. Laflamme [56] noted the influence of inflammation on many canine chronic diseases. Cave [57] noted the Maillard compounds within canned diets. The same applies to dry kibble as the heat and pressure used in processing is classic Maillard reaction with Amidori rearrangement that produces AGEs [58] and metaflammation. The same is as likely applicable to dogs as it is for humans. Much of the scientific community equates these responses with mammals as a whole [59]. Metaflammation creates an environment for cancer production [8] (Figure-1). This includes all chronic diseases that include cancer [36]. Metaflammation is referred to in the literature frequently as inflammaging [20] and occasionally as pseudo-inflammation [60]. Chronic inflammation or chronic systemic inflammation or sub-acute chronic inflammation terminology is also encountered as this new concept still struggles for a universally accepted nomenclature. This is also not the chronic inflammation, such as chronic bronchitis or pancreatitis and many others, that can be a lingering effect of acute inflammation. Metaflammation is more often silent until the accumulating effects of the chronic disease begin to appear after many years. Inflammatory markers are a hallmark and associated with cancer as well as other diseases commonly seen in aging [61]. Testing for inflammatory markers is one effective way to assess a level of metaflammation in the apparent state of normal health; much the same as cholesterol is diagnostic of buildup of pathology over time [62].

\section{Canine diet and cancer}

Oglivie notes that canine diets low in simple carbohydrates, but with moderate amounts of high quality protein, fiber, and omega- 3 fatty acids "reduce the risk of developing cancer, or the growth and metastases of established malignant disease. Nutritional intervention can be a powerful tool for controlling malignant disease and for reducing toxicity associated with chemotherapy and radiation therapy" [63]. Fermentable fiber is noted to improve incretin function [64] and there is some evidence that it has a positive influence on cancer of the colon [65]. The type of fermentable fiber influences digestion [66]. Diets rich in Omega-3 fatty acids improved the disease free interval and survival time in dogs with lymphoma who have received chemotherapy [67].

When we consider the dietary properties outlined above on the important areas of AGE's and metaflammation; the picture of cancer prevention, treatment, and incidence for reoccurrence is influenced considerably by the diet in both humans and dogs $[1,10,68-70]$. The connection between AGEs and metaflammation includes obesity, metabolic syndrome, GI system dysfunction, CNS inflammatory processes, integumentary disorders, and much more. Nutrition and lifestyle are being recognized to play a much more important role; just as the properties of adipokines are being uncovered and presenting a picture of a new, very important endocrine system that in humans is the largest in the body [71]. Since it exists in dogs there is little reason to think otherwise for that species [72].

\section{Brief history of contemporary dog food}

In the mid- $19^{\text {th }}$ century the first known commercial dog food, a biscuit, was developed by James Spratt in England. Spratt, who was from Ohio, brought his dry dog food to the USA $[73,74]$. After World War I with an abundance of horse meat, dog food was produced and sold in cans. Prior to that time dogs were mostly given scraps or just had food thrown out to them. Working dogs ate whatever was available to them from their working environment. During World War II cans become impractical due to the tin shortage. The use of dry kibble evolved [74]. Since World War II dog food has become primarily dry with most being pelletized; made from an animal meat and bone meal. This appears to be a shift in the diet of dogs [74]. Much like the major shifts in human nutrition [16,75-80] that is now associated with a pandemic of chronic disease. One sees a similar process occurring in the dog; another 
mammalian species. Added to this animal meal are various carbohydrates with corn, white potatoes, and grains being commonly employed. Fiber is often added that can be as poor quality as the dust and sweepings from different sources. This can equal a very poor diet that is harmful to the short and long term health of the dogs.

In addition there is some evidence, at least at some points in time when tested by FDA and some independent sources; that meat sources from the 4D's (dead, dying, diseased, disabled) are employed in the rendering $[81,82]$. That becomes a concern when the animal meal contains pentobarbital after rendering. There is some unease, since rendering may not adequately safeguard against bovine spongiform encephalopathy (mad cow disease) [83] in the meal. While it has not been reported to be a problem in dogs it is noted in cats [84]. There is also the mild risk of Creutzfeldt-Jakob disease in humans [83]. It has been reported that some humans consume dog food [85]. On June 15, 2012 the CDC reported salmonella poisoning in infants that was traced to a major manufacturer of dog food in the United States [86].

Dogs may have been forced to become more of an omnivore as opposed to a carnivore; but at what price? Hill [74] makes a case for dogs as primarily carnivores with omnivore capabilities based on dentation, and intestinal length. There is evidence that dogs do not need carbohydrates as long as there is sufficient protein and fat in their diet to supply the glucose precursors [74,87].

This may be a bit extreme as there is also evidence of the beneficial effects of fermentable fiber [66] that reported increased digestibility of dry matter: it also indicated an inverse relation for crude protein digestibility. The dog food used was $77 \%$ grain and protein (56\% rice and $21 \%$ poultry meal byproducts). The dog food had a glycemic load of 43 per 150 $\mathrm{g} /$ serving which is classified as a high glycemic load. The primary variable component for the four study groups were the cellulose and pectin content that amounted to $10 \%$ of the four study dog groups diet. The foods used were prepared by Hill's Science and Technology Center [66]. This is a poorly done cohort study that might be an evidence level grade of 4 (EVL 4) [88]. Not sure this study gives us much useful information about the normal digestion of the dogs when we only test what appears like a badly glycated, inflammatory diet; the type diet that has become the norm for all our dogs on these meal based kibble diets. There was a similar study done in 2008 that seems to have the same problems noted in the prior study; although to be fair it does note the fermentation at various portions of the gut with various soluble fibers [89]. This could be useful if the canine is not primarily a carnivore.

One has to wonder what the inflammatory effect of the diet was on the endothelium of the digestive tract of the dogs. Both rice and corn cause high glycemic indices in beagles [90] as they have high glycemic indexes, i.e. 89 and 60 respectively [91]. High glycemic load diets increase incidence of some cancers [92]. A meta-analysis [93] (EVL1) [88] done in 2008 found that in humans that higher postprandial glycaemia is a universal mechanism for disease progression; that included breast cancer as one of the chronic diseases. Whole grain consumption did not change inflammatory markers in a well-controlled evidence level 1 (EVL1) study [88,94]. Brownlee makes the point that all grains are not the same [94]. Poultry byproducts can include what is commonly referred to as "beaks and feathers" [95]. Nachman et al [95] report that feather meal contains arsenic that may be at risk for making it into the human food chain. Feather meal and/or chicken by-products that likely contain feathers are used in dog food [96]. When we look at chicken meat itself; Lasky et al [97]found arsenic levels higher than previously accepted which prompted this statement: "These concentrations are higher than previously recognized in chicken, which may necessitate adjustments to estimates of arsenic ingested through diet and may need to be considered when estimating the overall exposure to arsenic."

When combined with the combination of feather meal, meal from chicken and chicken by-products, and so called fresh chicken meal, that has been reduced to a dry kibble state (Maillard reaction), there is concern about arsenic in dog food. We have long known that arsenic causes many cancers [98].

One of the consequences in dogs over the past 50 years, as in humans, is an emerging incidence of chronic disease. Banfield Pet Hospital reports increased chronic disease in both cats and dogs in the past five years [99]. It is likely no coincidence that this problem runs parallel with escalating pandemic of chronic disease in humans worldwide. Whether this basic dietary change from carnivore to omnivore, if it is a change, is that important, is yet to be determined. There is reason to suspect that the problem may be as much food preparation and ingredient based as a drift, from carnivore to omnivore, that would have occurred, beginning 10,000 to 15,000 years ago, when dogs were domesticated by indigenous humans [100].

$\mathrm{Li}, \mathrm{Li}$, and Hutnik [101] noted the effect of dietary components on angiogenesis and propose it as a preventive measure for cancer. The scientific literature is replete with studies concerning the role of angiogenesis in prevention and treatment of many cancers $[10,101,102]$. While much of this is human related; there is good reason to suspect the same effects will occur in dogs.

\section{An evidence based dietary prevention, treatment, and recovery paradigm}

The canine dietary paradigm incorporates an AGE poor diet that utilizes an Omega-6 fatty acid to Omega-3 fatty acid ratio of less than 4 to 1 . It incorporates anti-inflammatory fermentable fiber 
Table-1. Evidence based references for canine cancer, metaflammation, and AGEs

\begin{tabular}{llcc}
\hline Cancer & Metaflammation (inflammation) \\
{$[1,2,4,8,13,23,42,46,56,103-105]$} & $3,23,42,46,56,103,105]$ & $\begin{array}{c}\text { Advanced glycation end products } \\
{[1,2,23,46,104,105]}\end{array}$ \\
\hline Prostate cancer & 3 & 3 & 3 \\
Mast Cell & 103,106 & 103,106 & --- \\
Sarcoma & $103,106,107^{*}$ & $103,106,107 *$ & 109 \\
Mammary Tumors & 108,109 & 108 & --- \\
Hemangiosarcoma & 110 & 110 & -- \\
B-cell lymphoma & 111 & 111 & 112 \\
Histiocytic sarcoma & 112 & --- & 113,116 \\
Lymphoma & 113 & -- & 118 \\
Osteosarcoma & $107,114^{*}, 115,116$ & $107,114 *$ & 118 \\
Mast cell & 117,118 & 117,118 &
\end{tabular}

This is not an exhaustive list, but a sample representative. * Inflammation unclassified in study, but the cancer responded to anti-inflammatory agents. Each numerical represents the reference no.

supported with anti-AGE and antioxidant natural ingredients with a low glycemic load.

The canine diet would consist of non-processed, no or low heat, from low AGE protein and fat sources. It would attenuate the protein and fat sources to diminish AGE formation by incorporating an acidic ingredient. It is devoid of grain. Part of the protein/fat source needs to be rich in Omega-3 fatty acids, preferably from cold water marine sources, as low on the food chain as possible. Fish oil supplements have been shown to be beneficial [67]. Sources of fermentable fiber should be incorporated that are antiinflammatory. Foods should not be exposed to high temperatures and pressures to avoid the Maillard reaction effect. If the protein sources were from grass$\mathrm{fed} /$ free range sources, it is much better for the health of the dogs. Ideally feedings would have a low glycemic load.

The AGE poor (low AGE and metaflammation) diet outlined above is offered as an alternative to the meal based kibbled diet observed today and to the high heat and pressure canned diet of today and post-World War I when horse meat was being canned for dogs. The theory being that avoiding these pathology-inducing problems, dogs will have less chronic disease including cancer. It is also postulated as a therapeutic modality for the treatment and recovery of cancer in dogs.

\section{Conclusion}

We have provided evidence from the scientific literature regarding the following:

- The effects of AGEs and metaflammation on the formation of chronic disease that includes cancer in both dogs and humans.

- Evidence that nutritional shifts are increasingly being looked at as a source of AGE formation with associated metaflammation in humans; to be suspected in dogs.

- Documented scientific evidence linking the occurrence of AGEs and metaflammation with food and lifestyle.

- Associated AGEs and metaflammation with expanding evidence of chronic disease that includes cancer.

- Provided a brief history of dog food.

- Linked the heat, pressure, and kibbling of dog food during processing with both the formation of AGEs and metaflammation.

- Offered a paradigm diet of known scientific evidence calculated to diminish or end the formation of these pathological processes related to chronic disease that includes cancer.

- The proposed unique diet paradigm offers opportunities to be tested for diminished AGE and metaflammation accumulation that results in diminished prevalence and incidence of cancer in dogs.

- The debate between dogs being a carnivore as opposed to omnivore is touched upon.

- The paradigm diet is suggested as a treatment and recovery aide from cancer as well.

\section{References}

1. Murua Escobar, H., Soller, J., Sterenczak, K., Sperveslage, J., Schlueter, C., Burchardt, B., Eberle, N., Fork, M., Nimzyk, R., Winkler, S., Nolte, I. and Bullerdiek, J. (2006) Cloning and characterization of the canine receptor for advanced glycation end products. Gene. 369:45-52.

2. Sterenczak, K., Willenbrock, S., Barann, M., Klemke, M., Soller, J., Eberle, N., Nolte, I., bullerdiek, J. and Murua Escobar, H. (2009) Cloning, characterisation, and comparative quantitative expression analyses of receptor for advanced glycation end products (RAGE) transcript forms. Gene. 434(1-2):35-42.

3. De Marzo, A., Coffey, D. and Nelson, W. (1999) New concepts in tissue specificity for prostate cancer and benigh prostatic hyperplasia. Urology. 53(Suppl 3a):29-39.

4. Miya, K., Misumi, K., Miyoshi, N., Aria, K., Fujik, M., Kubota, C., Salamoto, H. (2005)Interpreting gelatinase activity in tumor tissue and serum as a prognostic marker of naturally developing canine tumors. J Vet Med Sci. 67(8): 769-775.

5. Arulselvan, P., Wen, C.C., Lan, C.W., Chen, Y.H., Wei, W.C. and Yang, N.S. (2012) Dietary Administration of Scallion Extract Effectively Inhibits Colorectal Tumor Growth: Cellular and Molecular Mechanisms in Mice. PLoS One. 7(9):e44658.

6. Mederle, O., Mederie, N., Bocan, E., Ceausu, R. and Raica, M. VEGF (2010) expression in dog mastocytoma. Rev Med Chir Soc Med Nat Iasi. 114(1):185-188.

7. Kumar, V. (2012) Adenosine as an endogenous immunoregulator in cancer pathogenesis: where to go? Purinegic Signal. 9(2):145-65.

8. Lowe, B. and Storkun, W. (2011) Chronic inflammation and immunologic-based constraints in malignant disease. Immunotherapy. 3(10):1265-1274.

9. Scrivo, R., Vasile, M., Bartosiewicz, I. and Valesini, G. (2011) Inflammation as "common soil" of the multifactorial diseases. Autoimmun Rev. 10(7):369-374.

10. Sethl, G., Shanmugam, M., Ramachandran, L., Kumar, A. 
and Terganonkar V. (2012) Multifaceted link between cancer and inflammation. Biosci Rep. 32(1):1-15.

11. Stix, G. A. (2007) malignant flame. Understanding chronic inflammation, which contributes to heart disease, Alzheimer's and a variety of other ailments, may be a key to unlocking the mysteries of cancer. Sci Am. 297(1):60-67.

12. Egger, G. (2011) Obesity, Chronic Disease, and Economic Growth: A Case for "Big Picture" Prevention. Advances in Preventive Medicine. 26 (10): 149-158.

13. Zoran, D. (2010) Obesity in dogs and cats: a metabolic and endocrine disorder. Vet Clin North Am Small Anim Pract. 417-418:183-188.

14. Hickman, M. (1998) Interventional nutrition for gastrointestinal disease. Clin Tech Small Anim Pract. 13(4):211216.

15. Johnson, P. (2010) Dogs in Biomedical research. [Lecture]. http://www.uac.arizona.edu/vsc443/dogmodel/10_dog_as _models_lect.pdf. Accessed December 28, 2012.

16. Kozak, L., Koza, R. and Anunciado-Koza, R. (2010) Brown fat thermogenesis and body weight regulation in mice: relevance to humans. Int J Obes (Lond). 34(Suppl 1):S23-27.

17. Tvarijonaviciute, A., Ceron, J., Holden, S., Cuthbertson, D., Biourge, V., Morris, P. and German, A. (2012) Obesityrelated metabolic dysfunction in dogs: a comparison with human metabolic syndrome. BMC Vet Res. 8(1):147.

18. Hill, R. (2009) Conference on "Multidisciplinary approaches to nutritional problems". Symposium on "Nutrition and health". Nutritional theapies to improve health: lessons from companion animals. Proc Nutr Soc. 68(1):98-102.

19. Rowell, J., McCarthy, D. and Alvarez, C. (2011) Dog Models of naturally occurring cancer. Trends Mol Med. 17(7):380388.

20. Salminen, A., Kaarniranta, K. and Kauppinen, A. (2012) Inflammaging:disturbed interplay between autophagy and inflammasomes. Aging (Albany NY). 4(3):166-175.

21. Weber K, Schmahl W. and Munch G. (1998) Distribution of advanced glycation end products in the cerebellar neurons of dogs. Brain Res. 791(1-2):11-17.

22. Yuki, M., Itoh, H. and Takase, K. (2010) Serum alpha-1-acid glycoprotein concentration in clinically healthy puppies and adult dogs and in dogs with various diseases. Vet Clin Pathol. 39(1):65-71.

23. Murua Escobar, H., Meher, B., Richter, A., Becker, K., Flohr, A., Bullerdiek, J. and Nolte, I. (2003) Molecular characterization of the canine HMGB1. Cytogenet Genome Res. 101(1):33-38

24. Gil, A., Olza, J., Gil-Campos, M., Gomez-Llorente, C. and Aquilera, C. (2011) Is adipose tissue metabolically different at different sites? Int J Pediatr Obes. 6(Suppl 1):13-20.

25. Cook, A. and Cowan, C. (2008-2009) Adipose. Stembook [Internet].2008-2009. http://www.ncbi.nlm.nih.gov/ pubmed/20614613. Accessed Jan 7, 2013.

26. Tetè, S., Nicoletti, M., Saggini, A., Maccauro, G., Rosati, M., Conti, F., Cianchetti, E., Tripodi, D., Toniato, E., Fulcheri, M., Salini, V., Caraffa, A., Antinolfi, P., Frydas, S., Pandolfi, F., Conti, P. and Potalivo, G. (2012)Nutrition and cancer prevention. Int J Immunopathol Pharmacol. 25(3):573-581.

27. Gugliucci, A., Kotani, K., Taing, J., Matsuoka, Y., Sano, Y., Yoshimura, M., Egawa, K., Horikawa, C., Kitagawa, Y., Kiso, Y., Kimura, S. and Sakane, N. (2009) Short-Term Low Calorie Diet Intervention Reduces Serum Advanced Glycation End Products in Healthy Overweight or Obese Adults. Annals of Nutrition \& Metabolism. 54(3):197-201.

28. Tsukahara, H., Ohta, N., Sato, S., Hiraoka, M., Shukunami, K., Uchiyama, M., Kawakami, H., Sekine, K. and Mayumi, M. (2004) Concentrations of pentosidine, an advanced glycaiton end-product, in umbilical cord blood. Free Radic Res. 38(7):691-695.

29. Heerwagen, M., Miller, M., Barbour, L. and Friedman, J. (2010) Maternal obesity and fetal metabolic programming: a fertile epigenetic soil. Am J Physiol Regul Integr Comp Physiol.299(3):R711-722.
30. Koletzko, B., Brands, B., Poston, L., Godfrey, K. and Demmelmair, H. (2012) Early nutrition programming of long-term health. Proc Nutr Soc. 18:1-8.

31. Reik, W., Dean, W. and Walter, J. (2001) Epigenetic reprogramming in mammalian development. Science. 293 (5532): 1089-1093.

32. Cinti, S. (2011) Between brown and white: novel aspects of adipocyte differentiation. Ann Med.43(2):104-115.

33. Nikoopoulos, D., Theocharis, S. and Kouraklis G. Ghrelin (2010) a potential therapeutic target for cancer. Requl Pept. 163(1-3):7-17.

34. Sparkes, A. (2011) Feeding old cats--an update on new nutritional therapies. Top Companion Anim Med. 26(1):3742.

35. Bagnell, C., Steinetz, B. and Bartol, F. (2009) Milk-borne relaxin and the lactocrine hypothesis for materman programming of neonatal tissues. Ann N Y Acad Sci. 1160: 152-157.

36. Yamagishi, S., Ueda, S. and Okuda, S. (2007) Food-derived advanced glycation end products (AGEs): a novel therapeutic target for various disorders. Curr Pharm Des. 13(27):28322836.

37. German, A., Ryan, V., German, A., Wood, I. and Trayburn, P. (2010) Obesity, its associated disorders and the role of inflammatory adipokines in companion animals. Vet J. 185 (1):4-9.

38. Birlouez-Aragon, I., Morales, F., Fogliano, V. and Pain, J. (2010) The health and technological implications of a better control of neoformed contaminants by the food industry. Pathol Biol 58(3):232-238.

39. Uribarri, J., Woodruff, S., Goodman, S., Cai, W., Chen, X., Pyzik, R., Yong, A., Striker, G. and Vlassara, H. (2010) Advanced glycation end products in foods and a practical guide to their reduction in the diet. J Am Diet Assoc. 110(6): 911-916, e912.

40. Perez-Calvo, E., Castrillo, C., Baucells, M. and Guada, J. (2010) Effect of rendering on protein and fat quality of animal by-products. J Anim Physiol Anim Nutr 94(5):e154163.

41. Delgado-Andrade, C., Rufian-Herares, J., Nieto, R., Aquilera, J., Navarro, M. and Seiquer, I. (2010) Does the pelleting process affect the nutritive value of a pre-starter diet for sucking piglets? Ex vivo studies on mineral absorption. J Sci Food Agric. 90(5):898-905.

42. Stadler, R., Blank, I., Varga, N., Robert, F., Hau, J., Guy, P., Robert, M. and Riediker, S. (2002) Acrylamide from Maillard reaction products. Nature. 419(6906):449-450.

43. Friedman, M. and Levin, C. (2008) Review of methods for

the reduction of dietary content and toxicity of acrylamide. $J$ Agric Food Chem. 56(15):6113-6140.

44. Tareke, E., Rydberg, P., Karlsson, P. and Tornqvist, M. (2002) Analysis of acrylamide, a carcinogen formed in heated foodstuffs. JAgric Food Chem. 50(17):4998-5006.

45. Semba, R., Nicklett, E. and Ferrucci, L. (2010) Does accumulation of advanced glycation end products contribute to the aging phenotype? J Gerontol 65(9):963-975.

46. Sterenczak, K, Nolte, I. and Escobar, H. (2013) RAGE Splicing Variants in Mammals. In: Heizmann CW, ed. Calcium-Binding Proteins and RAGE. Vol 963: Humana Press. pp.265-276.

47. Luevano-Contreras, C. and Chapman-Novakofski, K. (2010) Dietary advanced glycation end products and aging. Nutrients. 2(12):1247-1265.

48. Uribarri, J., Cai, W., Sandu, O., Peppa, M., Goldberg, T. and Vlassara, H. (2005) Diet-derived advanced glycaiton end products are major contributors to the body's AGE pool and induce inflammation in healthy subjects. Ann N Y Acad Sci. 1043:461-466.

49. Tessier, F. and Birlouez-Aragon, I. (2012) Health effects of dietary Maillard reaction products: the results of ICARE and other studies. Amino Acids. 42(4):1119-1131.

50. Song, F. and Schmidt, A. (2012) Glycation and insulin 
resistance: novel mechanisms and unique targets? Arterioscler Thromb Vasc Biol. 32(8):1760-1765.

51. Ramasamy, R., Yan, S. and Schmidt, A. (2012) Advanced glycation endproducts: from precursors to RAGE: round and round we go. Amino Acids. 42(4):1151-1161.

52. Goldin, A., Beckman, J.A., Schmidt, A.M. and Creager, M.A. (2006) Advanced Glycation End Products: Sparking the Development of Diabetic Vascular Injury. Circulation. 114 (6):597-605.

53. Negre-Salvayre, A., Coatrieux, C., Inguerneau, C. and Salvayre, R. (2008) Advanced lipid peroxidation end products in oxidative damage to proteins. Potential role in diseases and therapeutic prospects for the inhibitors. $\mathrm{Br} J$ Pharmacol. 153(1):6-20.

54. Giunta, B., Fernadndez, F., Nikolic, W., Obregon, D., Rrapo, E., Town, T. and Tan, J. (2008)Inflammaging as a prodrome to Alzheimer's disease. J Neuroinflammation. 5: 51.

55. Egger, G. and Dixon, J. (2009) Obesity and chronic disease; always offender or often just accomplice? Br J Nutr. 102 (8): 1238-1242.

56. Laflamme, D. (2012) Companion Animals Symposium: Obesity in dogs and cats: what is wrong with being fat? $J$ Anim Sci. 90(5):1653-1662.

57. Cave, N. (2003) Chronic inflammatory disorders of the gastrointestinal tract of companion animals. NZ Vet J. 51 (6): 262-274.

58. Goldberg, T., Cai, W., Peppa, M, Dardaine V, Baliga B, Uribarri J, Vlassara H. (2004) Advanced glycoxidation end products in commonly consumed foods. J Am Diet Assoc. 104(8):1287-1291.

59. Asif, M., Egan, J., Vasan, S., Jyothirmayi, G.N., Masurekar, M.R., Lopez, S., Williams, C., Torres, R.L., Wagle, D., Ulrich, P., Cerami, A., Brines, M. and Regan, T.J. (2000) An advanced glycaiton endproduct cross-link breaker can reverse age-related increases in myocardial stiffness. Proc Natl Acad Sci U S A 97(14):2809-2813.

60. Graeber, M., Li, W. and Rodriques, M. (2011) Role of microglia in CNS inflammation. FEBS Lett. 585(23):37983805.

61. Macaulay, R., Akbar, A. and Hensen, S. (2012) The role of the T cell in age-related inflammation. Age .35(3):563-72.

62. Neuhouser, M.L., Schwarz, Y., Wang, C., Breymeyer, K., Coronado, G., Wang, C.Y., Noar, K., Song, X. and Lampe, J.W. (2012) A Low-Glycemic Load Diet Reduces Serum CReactive Protein and Modestly Increases Adiponectin in Overweight and Obese Adults. The Journal of Nutrition. 142(2):369-374.

63. Ogilvie, G. (1998) Interventional nutrition for the cancer patient. Clin Tech Small Anim Pract. 13(4):224-231.

64. Massimino, S., McBurney, M., Field, C., Thomson, A., Keelan, M., Hayek, M. and Sunvoid, G. (1998) Fermentable dietary fiber increases GLP-1 secretion and improves glucose homeostasis despite increased intestinal glucose transport capacity in healthy dogs. J Nutr. 128(10): 17861793.

65. Rose, D., DeMeo, M., Keshavarzian, A. and Hamaker, B. (2007) Influence of dietary fiber on inflammatory bowel disease and colon cancer importance of fermentation pattern. Mutr Rev. 65(2):51-62.

66. Silvio, J., Harmon, D., Gross, K. and McLeod, K. (2000) Influence of fiber fermentability on nutrient digestion in the dog. Nutrition. 16(4):289-295.

67. Ogilvie, G., Fettman, M., Mallinckrodt, C., Walton, J., Hansen, R., Davenport, D., Gross, K., Richardson, K., Rogers, Q. and Hand, M. (2000) Effect of fish oil, arginine, and doxorubicin chemotherapy on remission and survival time for dogs with lymphoma: a souble-blind, randomized placebo-controlled study. Cancer. Apr 88 (8): 1916-1928.

68. Chua, W., Clarke, S. and Charles, K. (2012) Systemic inflammation and prediction of chemotherapy outcomes in patients receiving docetaxel for advanced cancer. Support Care Cancer. 20(8):1869-1874.
69. Kim, M., Kim, K., Han, J., Lim, J. and Song, Y. (2011) Modulation of inflammatory signaling pathways by phytochemicals in ovarian cancer. Genes Nutr. 6(2):109115.

70. Kuniyasu, H., Oue, N., Wakikawa, A., Shigeishi, H., Matsutani, N., Kuraoka, K., Ito, R., Yokozaki, H. and Yasui, W. (2002) Expression of receptors for advanced glycation end-products (RAGE) is closely associated with the invasive and metastatic activity of gastric cancer. The Journal of Pathology. 196(2):163-170.

71. Stehno-Bittel, L. (2008) Intricacies of fat. Phys Ther. 88 (11): 1268-1278.

72. Ryan, V., German, A., Wood, I., Hunter, L., Morris, P. and Trayhurn, P. (2010) Adipokine expression and secretion by canine adipocytes: stimulation of inflammatory adipokine production by LPS and TNFalpha. Pflugers Arch. 460 (3): 603-616.

73. Burns, P. A. (2011) Brief History of Dog Food. In: Burns P, ed. Terrierman's Daily Dose. Vol 2011. Aug 9, 2008 ed. Arlington, VA2008.

74. Hill, S.R. (2010) Changing the metabolism of dogs (canis familiaris) and cats (Felis catus) at rest and during exercise by manipulation of dietary macronutrients. Palmerston North, New Zealand: Nutritional Science, Massey University.

75. Adler, C.J., Dobney, K., Weyrich, L.S., Kaidonis, J., Walker, A.W., Haak, W., Bradshaw, C.J.A., Townsend, G., Soltysiak, A., Alt, K.W., Parkhill, J. and Cooper, A. (2013) Sequencing ancient calcified dental plaque shows changes in oral microbiota with dietary shifts of the Neolithic and Industrial revolutions. Nat Genet. 45(4):450-5.

76. Adler, C.J., Haak, W., Donlon, D. and Cooper, A. (2011) Survival and recovery of DNA from ancient teeth and bones. Journal of Archaeological Science. 38(5):956-964.

77. Simopoulos, A. (2009) A Balanced Omega-6/Omega-3 Fatty Acid Ratio, Cholesterol and Coronary Heart Disease. 100: 12.

78. Simopoulos, A. (2008) The importance of the omeaga-6/ omega-3 fatty acid ratio in cardiovascular disease and the other chronic diseases. Exp Biol Med (Maywood). 233(6): 674-688.

79. Egger, G. (2012) In search of a germ theory equivalent for chronic disease. Prev Chronic Dis. 9:E95.

80. Egger, G. and Dixon, J. (2010) Inflammatory effects of nutritional stimuli: further support for the need for a big picture approach to tackling obesity and chronic disease. Obes Rev. 11(2):137-149.

81. O'Connor, J., Stowe, C. and Robinson, R. (1985) Fate of sodium pentobarbital in rendered products. Am J Vet Res. 48(8): 1721-1724.

82. Myers, M. (2004) CVM Scientists develop PCR test to determine source of animal products in feed, pet food. Veterinarian Newsletter [Online] http://www.fda.gov/ AnimalVeterinary/NewsEvents/FDAVeterinarianNewslette r/ucm093929.htm. Accessed December 27, 2012.

83. Taylor, D. and Woodgate, S. (2003) Rendering practices and inactivation of transmissible spongiform encephalopathy agents. Rev Sci Tech. 22(1):297-310.

84. USDA. (2011) BSE and the safety of pets. http://www.fda. gov/AnimalVeterinary/GuidanceComplianceEnforcement/ ComplianceEnforcement/BovineSpongiformEncephalopat hy/ucm142819.htm. Accessed December 28, 2012.

85. http://message. snopes.com/showthread.php? $\mathrm{t}=6517$. Accessed December 30, 2012.

86. CDC (2012) Human Salmonella Infantis infections linked to dry dog food- United States and Canada, 2012. Morbidity and Mortality Weekly Report (MMWR). 61(23):436.

87. Case, L. (2005) Nutrient requirements of the dog. The Dog: Its behaviror, nutrition and health. 2nd ed. Iowa, USA: Blackwell Publishing Professional.

88. CEBM (2009) Oxford Centre for Evidence-based Medicine Levels of Evidence. http://www.cebm.net/ index. aspx? o= 1025. Accessed December 27, 2012.

89. Bosch, G., Pellikaan, W., Rutten, G., van der Poel, A., 
Verstegen, M. and Hendriks, W. (2008) Comparative in vitro fermentation activity in the canine distal gastrointestinal tract and fermentation kinetics of fiber sources. J Anim Sci. 86(11):2979-2989.

90. Adolphe, J., Drew, M., Huang, Q., Silver, T. and Weber, L. (2012) Postprandial impairment of flow-mediated dilation and elevated methylglyoxal after simple but not comples carohydrate consumption in dogs. Nutr Res. 32(4):278-284.

91. http://www.health.harvard.edu/newsweek/Glycemic index_and_glycemic_load_for_100_foods.htm. Accessed February 19, 2013.

92. Hu, J., La Vecchia, C., Augustin, L., Negri, E., de Groh, M., Morrison, H. and Mery, L. (2013) Gyycemic index, glycemic load and cancer risk. Ann Oncol. 24(1):245-251.

93. Barclay, A., Petocz, P., McMillan-Price, J., Flood, V., Prvan, T., Mitchell, P., Brand-Miller, J. (2008) Glycemic index, glycemic load, and chronic disease risk--a meta-analysis of observational studies. Am J Clin Nutr. 87(3):627-637.

94. Brownlee, I., Moore, C., Chatfield, M., Richardson, D., Ashby, P., Kuznesof, S., Jebb, S. and Seal, C. (2010) Markers of cardiovascular risk are not changed by increased wholegrain intake: Whole heart study, a randomised, controlled dietary intervention. BrJ Nutr. 104(1):125-134.

95. Nachman, K., Raber, G., Francesconi, K., Navas-Acien, A. and Love, D. (2012) Arsenic species in poultry feather meal. Sci Total Environ. 417-418.

96. Lasekan, A., Abu Bakar, F. and Hashim, D. (2012) Potential of chicken by-products as sources of useful biological resources. Waste Manag. pil: S0956-053X(12):00367-00364.

97. Lasky, T., Sun, W., Kadry, A. and Hoffman, M. (2004) Mean total arsenic concentrations in chicken 1989-2000 and estimated exposures for consumers of chicken. Environ Health Perspect. 112(1):18-21.

98. Magos, L. (1991) Epidemiological and experimental aspects of metal carcinogenesis: physicochemical properties, kinetics, and the active species. Environ Health Perspect. 95:157-189.

99. http://www.vetdepot.com/increase-chronic-diseasesinfographic.html. Accessed December 27, 2012, 2012.

100. Clutton-Brock, J. (1977) Man-made dogs. Science. 197 (4311):1340-1342.

101. Li, W., Li, V., Hutnik, M. and Chiou, A. (2012) Tumor angiogenesis as a target for dietary cancer prevention. $J$ Oncol. 2012:879623.

102. Aggarwal, B., Ichikawa, H., Garodia, P., Weerasinghe, P., Sethi, G., Bhatt, I., Pandey, M., Shishodia, S. and Nair. M. (2006) From traditional Ayurvedic medicine to modern medicine: identification of therapeutic targets for suppression of inflammation and cancer. Expert Opin Ther Targets. 10(1):89-118.

103. Krol, M., Pawlowski, K., Majchrzak, K., Gajewska, M., Majewska, A. and Motyl, T. (2012) Global gene expression profiles of canine macrophages and canine mammary cancer cells grown as a co-culture in vitro. BMC Veterinary Research. 8(1):16.

104. Sterenczak, K.A., Willenbrock, S., Barann, M., Klemke, M., Soller, J.T., Eberle, N., Nolte, I., Bullerdiek, J. and Escobar, H.M. (2009) Cloning, characterisation, and comparative quantitative expression analyses of receptor for advanced glycation end products (RAGE) transcript forms. Gene. 434 (1-2):35-42.

105. Schmidt, A.M., Yan, S.D., Yan, S.F. and Stern, D.M. (2000) The biology of the receptor for advanced glycation end products and its ligands. Biochimica et Biophysica Acta (BBA) - Molecular Cell Research. 1498(2-3):99-111.

106. Chase, D., McLauchlan, G., Eckersall, P.D., Parkin, T., Pratschke, K. and Pratschke, J. (2013) Acute phase protein levels in dogs with mast cell tumours and sarcomas. Veterinary Record. 170(25):648.

107. Wolfesberger, B., Hoelzl, C., Walter, I., Reider, G.A., Fertl, G., Thalhammer, J.G., Skalicky, M. and Egerbacher, M. (2006) In vitro effects of meloxicam with or without doxorubicin on canine osteosarcoma cells. Journal of Veterinary Pharmacology and Therapeutics. 29(1):15-23.

108. Zuccari, D., Castro, R., Gelaleti, G. and Mancini, U. (2011) Interleukin-8 expression associated with canine mammary tumors. Genet Mol Res. 10(3):1522-1532.

109. Willenbrock, S., Braun, O., Baumgart, J., Lange, S., Junghanss, C., Heisterkamp, A., Nolte, I., Bullerdiek, J., Murua Escobar, H. (2012) TNF- $\alpha$ induced secretion of HMGB1 from non-immune canine mammary epithelial cells (MTH53A). Cytokine. 57(2):210-220.

110. Tamburini, B., Phang, T., Fosmire, S., Scott, M., Trapp, S., Duckett, M., Robinson, S., Slansky, J., Sharkey, L., Cutter, G., Wojcieszyn, J., Bellgrau, D., Gemmill, R., Hunter, L. and Modiano, J. (2010) Gene expression profiling identifies inflammation and angiogenesis as distinguishing features of canine hemangiosarcoma. BMC Cancer. 10(1):619.

111. Brunker, J. and Hoover, J. (2007) B-cell lymphoma in a dog with ehrlichiosis (Ehrlichia canis) and systemic histoplasmosis (Histoplasma capsulatum). Can Vet J. 48(3): 292-295.

112. Sterenczk, K. A., Kleinschmidt, S., Wefstaedt, P., Eberle, N., Hewicker-Trautwein, M., Bullerdiek, J., Nolte, I. and Escobar, M. (2011) Quantitative PCR and Immunohistochemical Analyses of HMGB1 and RAGE Expression in Canine Disseminated Histiocytic Sarcoma (Malignant Histiocytosis). Anticancer Research.31(5):1541-1548.

113. Sterenczk, K. A., Joetzke, A.E., Willenbrock, S., Eberle, N., Lange, S., Junghanss, C., Nolete, I., Bullerdiek, J. Simon, D. and Escobar, H.M. (2010) High-mobility Group B1 (HMGB1) and Receptor for Advanced Glycation Endproducts (RAGE) Expression in Canine Lymphoma. Anticancer Research. 30(12):5043-5048.

114. Wilson, H., Chadalapaka, G., Jutooru, I., Sheppard, S., Pfent, C. and Safe, S. (2012) Effect of Tolfenamic Acid on Canine Cancer Cell Proliferation, Specificity Protein (Sp) Transcription Factors, and Sp-Regulated Proteins in Canine Osteosarcoma, Mammary Carcinoma, and Melanoma Cells. Journal of Veterinary Internal Medicine. 26(4):977-986.

115. Mercer, N., Ahmed, H., Etcheverry, S., Vasta, G. and Cortizo, A. (2007) Regulation of advanced glycation end product (AGE) receptors and apoptosis by AGEs in osteoblast-like cells. Molecular and Cellular Biochemistry. 306(1-2):87-94.

116. Mercer, N., Ahmed, H., McCarthy, A., Etcheverry S, Vasta G. and Cortizo A. (2004)AGE-R3/galectin-3 expression in osteoblast-like cells: regulation by AGEs. Mol Cell Biochem. 266(1-2):17-24.

117. Misdorp, W. (2004) Mast cells and canine mast cell tumours. Areview. Veterinary Quarterly. 26(4):156-169.

118. Yoshimaru, T., Suzuki, Y., Inoue, T., Nishida, S. and Ra, C. (2008) Extracellular superoxide released from mitochondria mediates mast cell death by advanced glycation end products. Biochimica et Biophysica Acta (BBA) - Molecular Cell Research. 1783(12):2332-2343. 